\section{A realização fonética do galego e a do português: um estudo comparativo com o latim}

The phonetical performance of galician and portuguese:

a comparative study with

latin

Camilla da Silva MENDES (IFFluminense) camillamendes12@hotmail.com

Nathalia Reis de MEDEIROS (IFFluminense) nathalia.reism@gmail.com

Thiago Soares de OLIVEIRA (IFFluminense) so.thiago@hotmail.com
MENDES, Camilla da Silva;

MEDEIROS, Nathalia Reis de;

OLIVEIRA, Thiago Soares de. A

realização fonética do galego e a do

português: um estudo comparativo

com o latim. Entrepalavras,

Fortaleza, v. 7, p. 107-131, ago./dez. 2017.

Resumo: Este trabalho é resultado de pesquisa desenvolvida no Núcleo de Estudos Culturais, Estéticos e de Linguagens do Instituto Federal Fluminense, a partir do projeto intitulado "O Português Histórico e sua aplicabilidade na explicação de fenômenos fonéticos da Língua Portuguesa". Considerando que as línguas galega e portuguesa advêm do galego-português, um romance regional que se desenvolveu na parte ocidental da Península Ibérica, e também que ambas são oriundas do latim, este trabalho pretende realizar um estudo fonéticocomparativo entre esses três idiomas a fim de demonstrar que, apesar da origem comum, as realizações fonéticas do galego ainda se aproximam da pronúncia reconstituída latina, apontando para uma tradição na realização fonética. Adota-se, para tanto, o método comparativo a ser aplicado por meio da técnica de análise documental das Normas Ortográficas e Morfolóxicas do Idioma Galego, instituídas pela Real Academia Galega e pelo Instituto de Língua Galega com o intuito de unificar a ortografia e a morfologia dessa língua, em gramáticas da língua portuguesa e em compêndios latinos, especialmente no que toca à fonética. Embora existam diversos fonemas dialetais, trata-se aqui 
v. 7 (2) $107-131$ ago/dez 2017

108

apenas dos fonemas recolhidos nas Normas, ressaltando que o galego ainda tem muita semelhança com o português devido à origem comum. Como referencial teórico, utilizam-se pricipalmente Amarante (2015), Monteagudo (2012) e Faria (1958; 1970), além de outros. No mais, justifica-se este artigo em razão da escassez de trabalhos na seara em que se pretende adentrar e da relevância do tratamento comparativo dos aspectos fonéticos de línguas que estão ou estiveram em contato, como é o caso do galego e do português.

Palavras-chave: Fonética histórica. Galego-português. Línguas em contato.

Abstract: This work is the result of research developed at the Center for Cultural, Aesthetic and Language Studies of the Federal Fluminense Institute, based on the project entitled "Portuguese History and its applicability in the explanation of phonetic phenomena of the Portuguese Language". Considering that the Galician and Portuguese languages come from Galician-Portuguese, a regional novel that developed in the western part of the Iberian Peninsula, and also that both come from Latin, this work intends to carry out a phonetic-comparative study between these three languages in order To demonstrate that, despite their common origin, Galician's phonetic achievements still approach Latin reconstituted pronunciation, pointing to a tradition in phonetic achievement. For this purpose, the comparative method to be applied by means of the documentary analysis technique of the Orthographic and morphological Norms of the Galician language, instituted by the Galician Royal Academy and the Galician Language Institute with the purpose of unifying the spelling and morphology of this language, in grammars of the Portuguese language and in Latin compendiums, especially with regard to phonetics. Although there are several dialectal phonemes, these are only the phonemes collected in the Norms, emphasizing that the Galician still has much similarity with the Portuguese due to the common origin. As a theoretical reference, it is used mainly Amarante (2015), Monteagudo (2012) and Faria $(1958 ; 1970)$, besides others. In addition, this article is justified because of the scarcity of works in the area where it is intended to penetrate and the relevance of the comparative treatment of the phonetic aspects of languages that are or have been in contact, as is the case of Galician and Portuguese.

Keywords: Historical phonetics. Galician-Portuguese. Languages in contact.

\section{Considerações iniciais}

Partindo dos princípios de que a língua portuguesa e a língua galega ${ }^{1}$ surgiram de um romance denominado galego-português e de que esse romance é fruto de uma evolução lenta do latim vulgar, é possível pressupor que tais línguas têm semelhanças e particularidades por razões específicas do lugar onde se estabeleceram. Nesse sentido, este trabalho tem o intuito de resgatar a origem do galego-português, além de realizar um estudo fonético-comparativo entre o galego, o português e o latim.

Analisando o fato de que o galego é uma língua com pouca

\footnotetext{
${ }^{1}$ Apesar de o galego ter sido "rebaixado" a dialeto por Cintra (1971), considera-se, neste trabalho, que os idiomas derivados do latim vulgar são línguas, desprezando-se a diferenciação entre os conceitos de língua e de dialeto por não haver convergência entre os estudiosos do assunto, bem como por não ser este o foco do trabalho aqui desenvolvido.
} 
visibilidade, porém de rica história, além de muito pertinente para a história da língua portuguesa tal como é vista nos dias de hoje, surgiu o interesse em pesquisar a fundo como se sucederam a história e a fonética dessas duas línguas, com o objetivo de compreender o que motivou as diferenças fonéticas existentes entre elas e também o momento em que tomaram rumos históricos diferentes. Assim, a questão-problema que se pretende responder é: qual é a relação fonética mantida entre o galego, o português e o latim², tendo em vista a relação histórica existente entre tais línguas? A hipótese é a de que o galego, por ser considerado arcaico, aproxima-se foneticamente mais do latim do que do português, língua viva e dinâmica. Para isso é que se propõe uma comparação fonética entre a língua de origem, o latim, e duas línguas dele derivadas, o galego e o português.

Esse trabalho justifica-se pela intencionalidade de aumentar o leque de pesquisas acerca do galego e, principalmente, a sua história junto à língua portuguesa, visto que há grande escassez teórica sobre o assunto aqui tratado. Ainda que não seja possível precisar o tempo em que ambas as línguas nasceram, este trabalho busca relatar resumidamente os principais acontecimentos da fase do galegoportuguês, de maneira que seja possível compreender como o latim acabou criando e transformando um romance que, posteriormente, tornar-se-ia duas línguas foneticamente aproximadas.

Para a realização deste artigo acadêmico, foi necessário recorrer a diferentes pesquisas, gramáticas históricas, acordos ortográficos, uma vez que se levam em consideração três línguas e, consequentemente, três histórias e três manifestações fonéticas que, embora se cruzem muitas vezes, não deixam de ser três línguas ${ }^{3}$ distintas. Foram utilizadas

\footnotetext{
${ }^{2} \mathrm{~A}$ fonética latina utilizada neste trabalho é a da pronúncia reconstituída ou restaurada, visto que, na maioria das universidades brasileiras, esta é a pronúncia adotada por se tratar de um resultado de um estudo histórico-fonético profundo que foi capaz de reconstituir como os falantes do latim supostamente falavam. Note-se que, apesar de ser a pronúncia eclesiástica a realização oral viva da língua latina, não se pode aqui traçar uma comparação entre as línguas sob a perspectiva da pronúncia eclesiástica, por ser bastante italianizada, contendo vários traços de uma língua românica atual: o italiano. Além disso, não foi utilizada a suposta pronúncia do latim vulgar, que originou de fato as línguas neolatinas, pela dificuldade história de reconstituir essa forma de falar, que se afastava da modalidade clássica latina, sendo considerada por muitos como despojada e desviante.

3 Embora se utilize o termo "línguas", sabe-se que a língua latina originou também muitos dialetos. Contudo, este trabalho não distingue, na maioria da vezes, os termos "língua" e "dialeto", pois o que precipuamente diferencia ambos é o status político, ainda que existam vários fatores que podem ser utilizados para a caracterização de tais expressões.
} 
v. 7 (2)

$107-131$ ago/dez 2017

também ilustrações e tabelas para tornar mais fácil a compreensão do conteúdo discutido. Além disso, faz-se uso do método comparativo no âmbito da pesquisa bibliográfica, já que se trata aqui de um artigo teórico com pretensões de caráter qualitativo.

Metodologicamente, com o fito de contribuir para os estudos da área de descrição linguística, este artigo se ampara na pesquisa bibliográfica, dada a fonte de dados a que se recorre para a constituição do arcabouço teórico necessário à análise documental pretendida, sendo esta o instrumento adotado e estruturado da seguinte forma: a) avaliação preliminar do documento Normas Ortográficas e Morfolóxicas do Idioma Galego, instituídas pela Real Academia Galega e pelo Instituto de Língua Galega, apontando conceitos, interesses e conceitos-chave; b) reunião de todas as partes selecionadas e interpretação coerente com base na proposta apresentada; e c) a comparação propriamente dita entre o latim reconstituído, o português e o galego.

Por fim, é preciso mencionar que se abordam alguns acontecimentos da Península Ibérica durante a Idade Média, dado o fato de o galego-português ser um romance medieval. Pretende-se, assim, contribuir para o acervo de pesquisas sobre a proximidade existente entre o galego e o português e como a pronúncia do latim aproximase foneticamente do galego, considerado arcaico. Importante ressaltar também que este trabalho inscreve-se na relação entre as áreas da fonética histórica e da história da língua portuguesa. Fatos históricos serão relatados com o objetivo de contextualizar o assunto.

\section{O galego-português: um romance regional medieval}

A expressão "galego-português" é capaz de remeter ao período de origens da língua e literatura portuguesas, já que o português não surgiu diretamente do latim. O romance galego-português nasceu entre os séculos IX e XII, sendo uma evolução natural da língua latina vulgar (falada) nas terras de uma velha província denominada Galaica (MONTEAGUDO, 2012; NUNES, 1969).

Segundo Monteagudo (2012), o galego-português tem relação direta com as duas partes do território onde nasceram o galego e o português. Esses lugares são: o norte do rio Minho e a Galiza estrita, os quais correspondem atualmente ao território da Galiza e têm como núcleo o antigo romano galaico lucense; a sul do Minho e a norte do Douro, o condado, depois reino de Portugal, que tem como núcleo 
originário o antigo convento romano galaico bracarense. Sendo assim, a denominação galega seria capaz de abranger tanto a Galiza lucense quanto a Galiza bracaense, mas tal denominação se transformou a ponto de não ter o mesmo significado restrito atual.

No século XII, Portugal se separou da Galiza, que se tornou, então, região vizinha, assim como os reinos de Leão, Castela e de Espanha. Tal fronteira acabou sendo definitiva. Durante o período em que Lisboa se tornou a capital do país, a língua galego-portuguesa se espalhou pelas regiões meridionais, que até então falavam dialetos moçárabes. É importante ressaltar que, entre os séculos VIII e XIV, a língua comum era o galego-português nascido no Norte, consoante aponta Teyssier (1982). Vide o Mapa 1, representativo do território à época:

Mapa 1 - Representação da Península Ibérica e do território galego-português

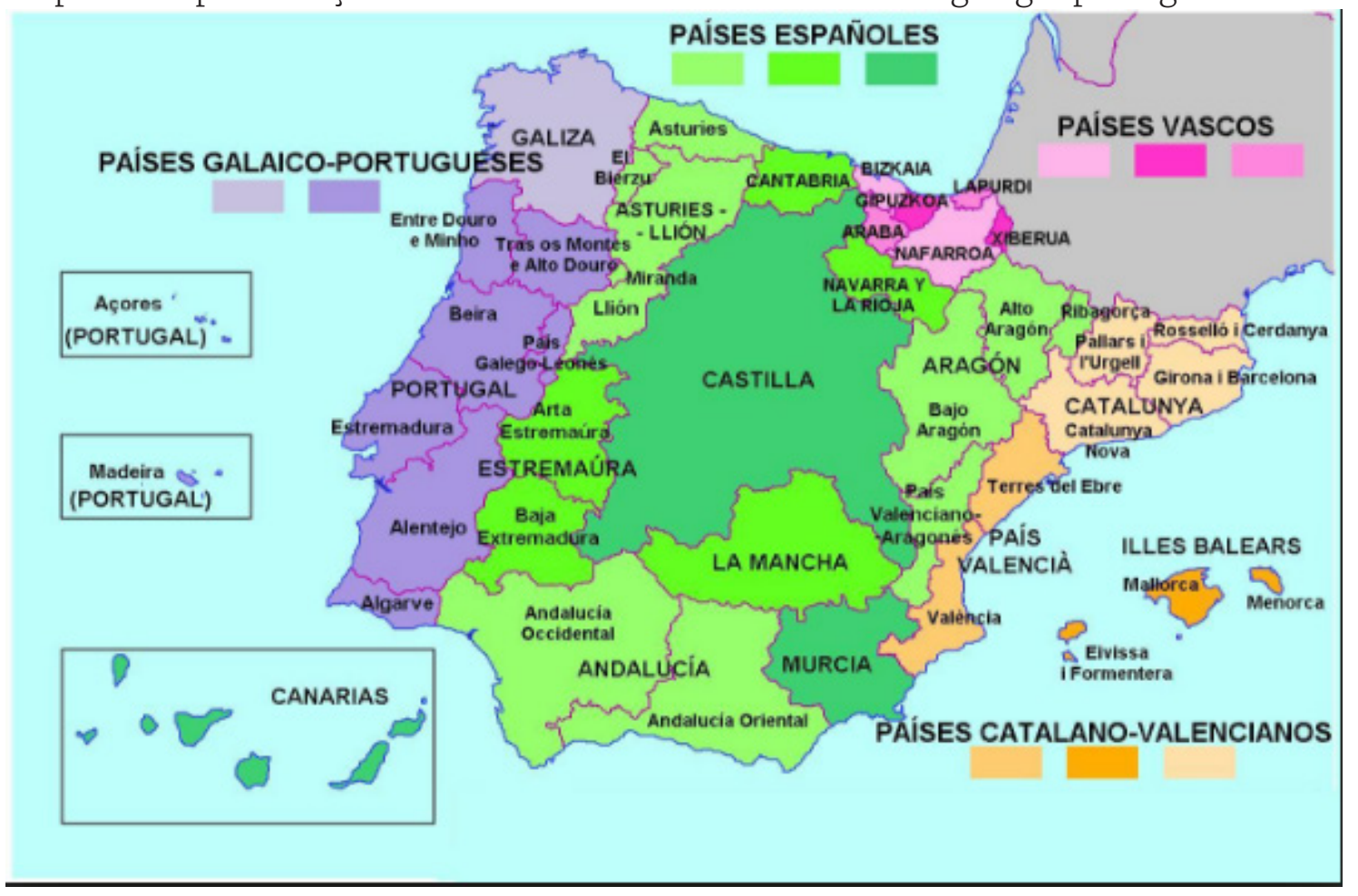

Fonte: Desperta de seu sono - Disponível em: http://despertadoteusono.blogspot. com.br/2013/07/o-que-um-brasileiro-deve-saber-sobre.html

O território demarcado no Mapa 1 foi se modificando com o passar do tempo. Os reis e nobres da Galiza do Norte tomaram posse do galego, cortando assim o processo natural de guerra para o sul com o intuito de conquistar novos domínios. Porém, esses reis e nobres tinham a ideia de serem antigos e velhos, o que os levou a aspirar um importante papel no contexto peninsular, que, por fim, resultou no domínio das terras 
v. 7 (2)

$107-131$ ago/dez 2017

do reino de Leão e, logo mais, da coroa do Reino Central, herdeiro da Hispânica Visigótica. Importante ressaltar que a divisão de Galiza em dois reinos não teve efeitos sobre a língua galega, uma vez que ela era falada no Norte e no Sul'4 (BANHOS, 2006).

Em meados do século XIV, ocorreu uma disputa pela coroa de Castela. Os galegos apoiaram Dom Pedro I, que perdeu o trono para Dom Henrique II. Em virtude desse acontecimento, a Galiza foi desprestigiada, e seus dirigentes foram sendo substituídos por castelhanos que obtinham a confiança do rei. Já no século XV, a Galiza novamente perdeu a disputa na qual apoiava Joana, que perdeu para Isabel, governante que, durante seu reinado, repreendeu a Galiza, dando origem aos "Séculos Escuros". De tal maneira, popularizou-se um estereótipo pela Península Ibérica do galego como um imigrante pobre e rústico, o que atribuiu total desprestígio à língua galega (AREÁN-GARCIA, 2011).

De acordo com Banhos (2006), na fase denominada de Séculos Obscuros $^{5}$, na qual o português do território de Galiza se torna uma língua sem escrita, porém falada por grande parte da população, com exceção apenas dos servidores e das classes dominantes, os quais eram castelhanos, o português passou a ser visto como uma língua inútil para o Estado, ou seja, os habitantes da Galiza faziam uso de uma língua, porém a oficial era outra, e era nessa outra língua que se realizava a escrita, ainda que, nessa época, a escrita não fosse relevante na vida da sociedade.

Teyssier (1982), por sua vez, explica que a divergência existente entre o castelhano e o português, sendo este português, na verdade, o galego-português medieval, dá-se porque o castelhano foi levado para o Sul através da Reconquista ${ }^{6}$, enquanto o português moderno foi levado para a região centro-sul, local onde Lisboa fica localizada atualmente. De tal maneira, é possível compreender que a diferença existente entre os dois idiomas se dá devido às colonizações que direcionaram os povos para lugares distintos, dividindo assim uma grande área.

Apesar disso, foi preciso muito tempo até que o povo reconhecesse o português como uma nova língua. Para ajudar nesse processo de irradiar a cultura da Idade Média, foi necessária a ajuda de duas

\footnotetext{
$\overline{4}$ Até então, Portugal também falava galego.

${ }^{5}$ Areán-Garcia (2011) se refere à mesma fase como "Séculos Escuros".

${ }^{6}$ Em 711, os muçulmanos invadem e conquistam a Península Ibérica, incluindo Portugal e Galiza. Os mulçumanos tinham o árabe como língua de cultura. Eis que a Reconquista é nome dado ao processo em que os cristãos vão gradativamente expulsando esses povos para o Sul. É nesse período que Portugal se torna um reino independente.
} 
instituições: os mosteiros7 7 que traduziram as obras latinas, francesas e espanholas, e a Corte, que convergia os interesses nacionais, escrevendo e aprimorando a língua literária. Dessa maneira, a língua portuguesa passou a ter maior prestígio e conhecimento por parte da sociedade, de acordo as informações de Castilho (2009).

Nessa linha de raciocínio, o galego se isola do português a partir do século XI, porém é só a partir do século XVI que o galego deixa de ser cultivado como língua literária, sobrevivendo apenas no seu uso oral. Além disso, o galego sofre uma série de mudanças fonéticas que o afastaram do português, como o ensurdecimento das fricativas sonoras $z$, s e j, que se confundem com ç, ss e x, a pronúncia interdental do antigo ç, entre outras. Nos séculos XIX e XX, ocorre o Renascimento galego, momento em que escritores e filósofos lutam em prol da elaboração de uma língua unificada. Contudo, acerca do assunto, observa-se que,

Pela sua fonética, pela sua morfologia, pelo seu vocabulário, pela sua sintaxe e mesmo pela sua ortografia, este galego moderno é já uma língua diferente do português - diferente, contudo suficientemente próxima para que, em condições favoráveis, a intercompreensão ainda seja possível (TEYSSIER, 1982, p. 34).

Observando as palavras do autor citado acerca do Renascimento galego e sobre a possível criação de uma língua unificada, percebese que, apesar do certo distanciamento entre o português e o galego nos níveis fonético, morfológico, lexical, sintático e ortográfico, os indivíduos que manejavam essas duas línguas eram capazes (e ainda o são) de se entender mutuamente.

Assim, havia três línguas peninsulares: o galego-português, a oeste; o castelhano, no centro; e o catalão, a leste. A língua galegoportuguesa do norte sofre uma transformação lenta e gradativa até chegar a se tornar o português. A região onde se localizava esse Reino Independente ficou despovoada e, com intuito de resolver esse problema, os conquistadores cristãos povoaram-no com pessoas do norte, o que difundiu ainda mais o galego-português por toda parte central e meridional (TEYSSIER, 1982). Eis abaixo o Mapa 2, representativo das regiões onde se falam as diversas línguas e dialetos da Península Ibérica:

$\overline{7}$ Mosteiros de Santa Cruz e Alcobaça. 
v. 7 (2)

$107-131$ ago/dez 2017

Mapa 2 - Breve Histórico das línguas e dialetos da Península Ibérica.

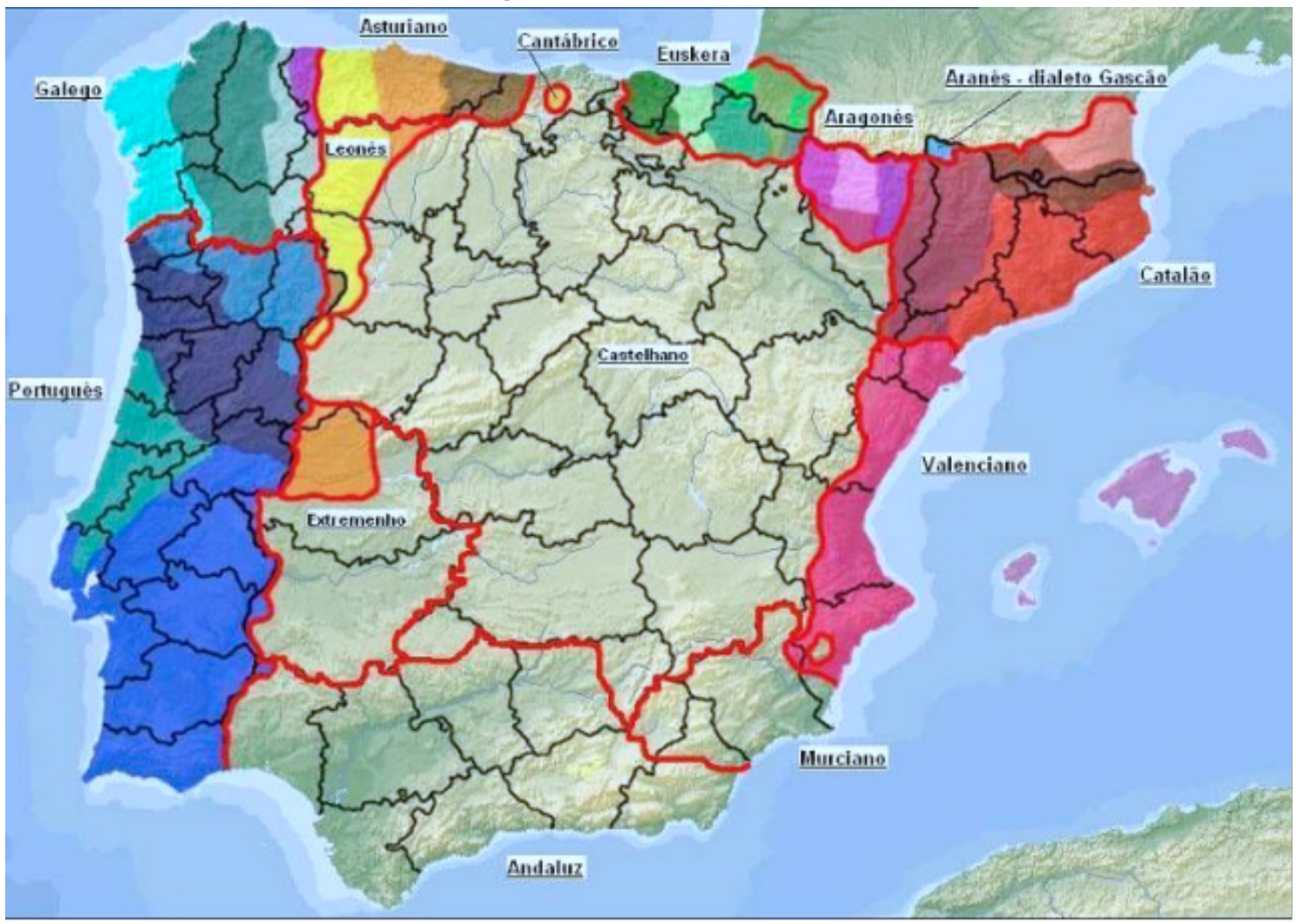

Fonte: AREÁN-GARCIA (2011)

O Mapa 2 representa a atual divisão dialetal da Península Ibérica, na qual é possível observar a presença do português, do galego, do leonês, do estremenho e, principalmente, do castelhano, isso porque a força do castelhano era tanta que não permitia que outra língua fosse imposta a seu povo e, se o português conseguiu se manter, foi devido ao fato de ser um reino forte e independente, capaz de se desenvolver nas regiões que conquistou ao longo dos séculos. O galego, por sua vez, só foi capaz de sobreviver devido às suas zonas periféricas ${ }^{8}$.

Mais especificamente sobre a língua portuguesa, são reconhecidos historicamente três períodos, sendo eles: o pré-histórico (séc. V ao IX), marcado pelo romance lusitânico; o proto-histórico (séc. IX ao XII), quando os textos são redigidos em latim bárbaro ${ }^{9} \mathrm{com}$ apenas algumas palavras em português; e o histórico (séc. XII ao XVI), que é o período

${ }^{8}$ Leonês, aragonês e euskera foram contidos pelo castelhano.

${ }^{9}$ Após o quase total desaparecimento da nobreza romana pela invasão dos bárbaros em 711 d. C., o latim literário deixou de ser utilizado, sendo acolhido pela igreja, onde foi cultivado. O latim bárbaro caracterizava-se pela utilização ora de termos populares ora de clássicos pelos tabeliães. Estes produziam documento públicos mesclando os ditames da gramática latina ao despojamento do latim vulgar influenciado pelas sucessivas irrupções bárbaras (NUNES, 1969). 
em que os textos são integralmente escritos em português (galegoportuguês, na verdade), podendo ser divididos em duas fases: o período arcaico (séc. XII ao XVI) e o moderno (séc. XVI em diante) (OTHERO, 2003). Nesse período arcaico, ainda não está formado exatamente o português, e sim uma mistura, sendo esta o romance galego-português, que se estendeu de Galiza até Algarve (SILVA, 2010).

Após a independência e, consequentemente, a consolidação de Portugal, o território galego se anexou ao reino de Castela e, assim, as pequenas diferenças dialetais foram sendo acentuadas a ponto de então se tornarem duas línguas: o galego e o português. Foi a partir da publicação de gramáticas da língua, no século XVI, fase do português moderno, que o português passou a ter formas definitivas conforme é visto até hoje (SILVA, 2010).

Dessa forma, percebe-se o galego-português como uma língua falada por uma vasta área, dando origem a outras duas línguas autônomas, sendo: o galego e o português. Tal separação se deu principalmente por razões políticas, já que, durante os XIV e XV, os representantes apoiados por Galiza perdem o trono duas vezes consecutivas e acabam tendo a sua língua desprestigiada, iniciando os "Séculos Escuros". Do nascimento do galego-português até a sua separação passaram-se quatro séculos, tempo suficiente para que ambas as línguas deixassem uma na outra traços observáveis indicativos de sua origem comum.

Devido à expansão marítima de Portugal, a partir do século XV, a língua portuguesa falada pelo povo se disseminou por todo o mundo, como anteriormente havia ocorrido com o latim. São grandes nomes como Pedro Álvares de Cabral e Vasco da Gama que levam aos vários rincões do mundo a língua portuguesa, a qual deram forma e prestígio para diversos países, como ocorreu no Brasil. Consequentemente, é possível dizer que o português sofreu diversas mudanças, não a ponto de se tornarem línguas distintas, mas a ponto de sofrerem finitas adaptações a cada povo que passara a fazer uso da mesma (OTHERO, 2003; SILVA, 2010).

Por fim, é importante lembrar que em Pontos de Gramática Histórica, de Ismael Coutinho (1974), um capítulo inteiro é dedicado às línguas românicas ${ }^{10}$, ou seja, às línguas provenientes do latim (vulgar), como é o caso do português. Nesse capítulo, o autor explica como as diferenças se sucederam de forma que uma única língua (o latim) desse

${ }^{10}$ Português, espanhol, catalão, francês, provençal, italiano, reto-romano, dalmático, romeno e sardo são as 10 línguas românicas, segundo Coutinho (1974). 
v. 7 (2)

$107-131$ ago/dez 2017

origem a diversas línguas e dialetos. Note-se que a principal causa defendida por Coutinho (1974) é a política. Uma vez que um povo está politicamente sujeito a outro, a unidade linguística se mantém forte; quando, porém, esse laço é desfeito, as divergências no que tange à língua começam a surgir.

\section{As Normas ortográficas e morfolóxicas do idioma galego: a realização fonética das letras}

O galego pôde, por certo tempo, ser considerado um dialeto11 localizado no território que compreende a Galiza, visto que, assim como aponta Rodríguez (1996), tal unidade linguística, que se rendeu à imposição da língua castelhana, manteve-se estática durante muitos séculos, ou seja, quase sem cultivo literário após a separação do português, o que contribuiu para um conservadorismo fonético que muito se aproxima do latim, notável em alguns aspectos do falar galego.

No entanto, há grandes esforços para munir tal unidade linguística de instruções normativas, sendo a primeira delas, de caráter sólido e embasado, datada de 1977, denominada de Bases pra unificación das normas lingüísticas do galego (1977). Essa iniciativa de normatização, promovida pelo Instituto da Língua Galega, surgiu juntamente com a prática do galego escrito e a hipótese de sua oficialização, seguida de uma série de tentativas e revisões até que se alcançasse a primeira codificação normativa da língua galega, que contou com suporte acadêmico e científico, utilizado nesta pesquisa (REAL ACADEMIA GALEGA, 2012).

À vista disso, é possível assimilar que, uma vez que o galego distingue-se do português no quesito evolução, o mesmo ainda possui traços fortes da língua que lhe deu origem, o latim. Assim sendo, ter conhecimento a respeito da fonética galega a fim de notar sua evolução do latim até os dias atuais é fundamental e, tendo em vista tal fato, será abordado abaixo o alfabeto galego com auxílio do documento Normas ortográficas e morfolóxicas do idioma galego, realizado pela Real Academia Galega em conjunto com o Instituto de Língua Galega, acompanhado de uma análise fonética. Eis o Quadro 1:

\footnotetext{
${ }^{11}$ José Pereira da Silva (2010) considera dialeto como unidade não autônoma que só pode receber status de língua caso circunstâncias político-sociais façam do mesmo um instrumento literário.
} 
Quadro 1 - Alfabeto galego

\begin{tabular}{|c|c|c|}
\hline Letra & Nome & Pronúncia \\
\hline 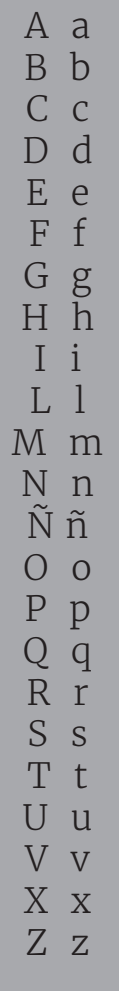 & $\begin{array}{c}\text { A } \\
\text { Be } \\
\text { Ce } \\
\text { De } \\
\text { E } \\
\text { Efe } \\
\text { Gue } \\
\text { Hache } \\
\text { I } \\
\text { Ele } \\
\text { Eme } \\
\text { Ene } \\
\text { Eñe } \\
\text { O } \\
\text { Pe } \\
\text { Que } \\
\text { Erre } \\
\text { Ese } \\
\text { Te } \\
\text { U } \\
\text { Uve } \\
\text { Xe } \\
\text { Zeta }\end{array}$ & $\begin{array}{c}{[\mathrm{a}]} \\
{[\mathrm{b}]} \\
{[\mathrm{s}],[\mathrm{k}]} \\
{[\mathrm{d}]} \\
{[\mathrm{e}],[\mathrm{e}]} \\
{[\mathrm{f}]} \\
{[\mathrm{g}] \text { ou [h] }} \\
- \\
{[\mathrm{i}]} \\
{[\mathrm{l}]} \\
{[\mathrm{m}]} \\
{[\mathrm{n}]} \\
{[\mathrm{n}]} \\
{[\mathrm{o}],[\mathrm{O}]} \\
{[\mathrm{p}]} \\
{[\mathrm{k}]} \\
{[\mathrm{r}] .[\mathrm{r}]} \\
{[\mathrm{s}]} \\
{[\mathrm{t}]} \\
{[\mathrm{u}]} \\
{[\mathrm{b}]} \\
{[\mathrm{g}],[\mathrm{ks}]} \\
{[\mathrm{s}]}\end{array}$ \\
\hline
\end{tabular}

Fonte: Real Academia Galega

Ao observar o alfabeto ilustrado no Quadro 1, não se faz necessária uma reflexão profunda para detectar algumas peculiaridades presentes no mesmo. Tais peculiaridades não são por acaso e possuem suas devidas explicações pautadas em normas estabelecidas no documento utilizado como base desta pesquisa. Procura-se compreender, neste momento, como são realizados os fonemas em galego, desconsiderando quaisquer variações linguísticas pertencentes a tal unidade, uma vez que serão utilizadas informações do que se compreende como norma-padrão do falar galego.

A primeira e talvez mais óbvia das peculiaridades detectadas seja o fato de que o alfabeto galego é composto por 23 letras, ou seja, há a ausência das letras "j", "k", "w", "y" e "ç", sendo que está última é um fonema sibilante que ocorre na língua, mas não é representado graficamente. Entretanto, de acordo com as Normas (2012, p. 16), tais letras são encontradas grafadas tanto em palavras tomadas de outras línguas, como "Jefferson, Eça de Queirós, Kant, kantiano, Darwin, darwinismo, wagneriano, byroniano etc.", quanto em alguns casos de textos escritos na época do galego medieval. 
v. 7 (2) $107-131$ ago/dez 2017

Já no caso do "ç", Rodríguez (1996, p. 3) pontua que existe uma equivalência entre "ç" utilizado no português brasileiro e a letra "q" empregada em galego. Tomando a palavra "caça", como exemplo, em galego seria escrito "caqa" e realizado foneticamente como "kaka", sendo o primeiro $[\mathrm{k}]$, a representação fônica do "c" e o segundo do "q". Já o "j", assim como sua ocorrência fonética semelhante "ge" e "gi" como o "ç", também não faz parte do alfabeto galego. Dessa forma, sua representação se dá com o fonema "x", como em "gal. xente, [jente], port. gente" (RODRÍGUEZ, 1996, p. 5).

Outra ocorrência no alfabeto galego que merece ressalva é a realização do "h" que, de acordo com as Normas (2012, p. 18) analisadas, embora sua grafia permaneça em muitas palavras galegas como "horta" e "prohibir", foneticamente não possui valor algum. Nessa linha de raciocínio, tal reflexão leva ao questionamento a respeito da realização fonética do "h" nos dígrafos "ch" e "nh", visto que, nessas situações, o "h" encontra-se junto de uma consoante para formar um único som.

Sobre o dígrafo "ch", Debowiak (2008, p. 25) apresenta o exemplo da palavra "chover", que é realizada em galego como "tfoßer", ou seja, o dígrafo foneticamente possui valor de " $\mathrm{x}$ ", responsável por produzir um chiado em sua pronúncia. Já o dígrafo "nh", que pode ser encontrado em alguns pronomes e numerais femininos, ainda é alvo de discussões segundo Rodríguez (1996). No entanto, o autor descreve a realização fonética desse dígrafo dizendo que "ocorre uma prolação nasal da vogal anterior, seguida de leve pausa antes da pronúncia do a seguinte" (RODRÍGUEZ, 1996, p. 3). É o caso de "unha" (uma), por exemplo.

Dando seguimento à observação do alfabeto apresentado, notase que, além do " $n$ " comum, existe no galego o "ñ". Fruto de uma palatização ${ }^{12}$ na passagem do latim para o galego, o "ni + vogal" se transformou em "ñ", como em "seniorem > señor", encontrado nas Normas (2012, p. 19). Há ocorrências também de "ne + vogal" em vineam > Viña (p. 19), "mni + vogal" em somniare > soñar (p. 19), dentre outras. Ainda no mesmo raciocínio, fenômeno idêntico ocorreu com a letra "l", como no exemplo "filium > fillo" (p.19), em que o "li + vogal" sofreu palatização, tornando "ll".

Outra ocorrência no falar galego, não tão desconhecida aos olhos de um falante do português de Portugal, são as grafias "b" e "v". Curiosamente,

${ }^{12}$ Ximenes (2003, p. 59) conceitua palatização como "processo de mudança que ocorre quando os sons vocálicos ou consonantais alteram o seu ponto de articulação palatal", e ainda afirma que tal fenômeno depende do contexto. 
ambas representam um mesmo som, como na palavra "chover", proferida por um falante galego como "tfoßer", por exemplo. Em Portugal é possível encontrar tal ocorrência nos dialetos setentrionais transmontano e altominhoto, devido à fronteira com a Galiza, que acaba por influenciar na fonética portuguesa, sendo esse mesmo fenômeno conhecido pelo nome de "betacismo", como aponta Debowiak (2008, p. 25).

O " $\mathrm{x}$ ", penúltima letra do alfabeto galego, possui mais de uma realização fonética diferente. Pronuncia-se o " $\mathrm{x}$ " de forma chiada ( () em palavras como "xente" e "madeixa" e também há o "x" em forma de um encontro consonantal fonético [ks], denominado por Bechara (2015, p. 74) como dífono, que nada mais é do que uma letra com som de duas, como em "sexo".

O fato de a letra " $z$ " ter um "s" como representação fonética se deve ao fato de não existir o fonema [z] no galego. No português, existe o fonema $[z]$ como em "azedo", diferentemente do " $z$ " que é pronunciado em galego com som de "s". A palavra "azul", por exemplo, seria pronunciada no português brasileiro com o sonoro " $z$ " em seu fonema $[z]$, entretanto, no galego, tal palavra seria pronunciada com som surdo de " $\mathrm{s}$ ", mas apenas na fonética, pois graficamente o " $\mathrm{z}$ " está presente em palavras galegas como "zapato", "cazar" e "zoco", exemplificadas em meio às Normas (2012).

Em relação aos dígrafos, no galego são encontrados alguns semelhantes aos realizados no português, tais como "ch", "gu" "nh", "qu" e "rr", e apenas um outro graficamente desconhecido pelos falantes do português, o "ll". No entanto, devido à necessidade de adiantar informações para melhor compreensão, os dígrafos "ch", "nh" e "ll", já foram abordados acima. Resta aqui tratar dos dígrafos "gu", "qu" e "rr" realizados no galego. Abaixo, no Quadro 2, será esboçada a realização fonética dos dígrafos galegos: 
v. $7(2)$ 107-131 ago/dez 2017
Quadro 2 - Realização fonética dos dígrafos galegos

Letra

Nome

Pronúncia

\begin{tabular}{c|c} 
CH & Ce hache \\
NH & Ene hache \\
GU & Gue u \\
QU & Que u \\
RR & Erre dobre \\
LL & Ele dobre
\end{tabular}

Fonte: Real Academia Galega

Neste ponto, faz-se necessária a conceituação de dígrafo, que "é o emprego de duas letras para a representação gráfica de um só fonema já que uma delas é letra diacrítica" (BECHARA, 2015, p. 74). Dentro dessa definição, Bechara (2015) traz outro conceito pertinente, o de letras diacríticas, as quais se juntam a outras letras para lhes atribuir um valor fonético diferente e conceber um dígrafo. Na língua portuguesa, as letras diacríticas são: "h", "r", "s", "c", "ç", "u”, "m”, e "n".

No galego também ocorre dessa forma. O dígrafo "gu", por exemplo, é empregado antes de "e" ou " $i$ ". No entanto, nos demais casos, o "g" é utilizado sozinho, como em "gando", "gomo" e "glosa". O mesmo ocorre com o dígrafo "qu", incumbido de formar o som de [k] em "pequeno", "queixo" e "quilo". Já o "rr", assim como no português, é empregado quando encontrado em posição intervocálica, como em "carro" e "ferro".

Por fim, é preciso ressaltar que as observações aqui tecidas não abarcam todas as ocorrências fonéticas do galego, no entanto elas são necessárias para que seja possível traçar um paralelo entre o latim, o galego e o português, visto que o objetivo deste trabalho é demonstrar que a fonética galega ainda se aproxima do latim reconstituído em alguns aspectos, realizando-se de forma mais conservadora se comparada ao português.

\section{O estudo comparativo: latim de pronúncia reconstituída, galego e português}

Antes de desenvolver as comparações a serem realizadas aqui, é necessário compreender o motivo pelo qual se deu a escolha do latim em sua pronúncia reconstituída como ponto de partida nesta pesquisa, uma 
vez que são consideradas três noções de pronúncias do latim, de acordo com Amarante (2015). A primeira delas é a tradicional, semelhante à pronúncia das línguas modernas. A segunda é a eclesiástica ou romana, utilizada por membros da igreja católica. E a terceira, a reconstituída, também chamada de restaurada, que visa articular os sons do latim de acordo com a pronúncia da época clássica da língua (AMARANTE, 2015).

Diante disso, considera-se aqui a pronúncia reconstituída, dado que a mesma é fruto de pesquisas fonéticas que visavam recompor o latim como supostamente era falado na era clássica, ou seja, o chamado latim clássico que era considerado "a língua das classes cultivadas" (WILLIAMS, 1986, p.15). No entanto, foi o latim vulgar que deu origem às línguas românicas na medida em que o latim clássico ia desaparecendo, como aborda Williams (1986).

Na verdade, o que ocorre é que não há um consenso sobre a pronúncia do latim vulgar, devido à sua diversidade de dialetos e o fato de não existirem documentos que comprovem sua existência, ou seja, trata-se de "uma língua reconstruída de fragmentos heterogêneos e em grande parte na base de hipótese" (WILLIAMS, 1986, p. 15). Logo, o latim reconstituído tende a ser preciso e embasado teoricamente o suficiente para servir de comparação capaz de mostrar que o galego mantém certa tradição em sua fonética.

Tendo tal delimitação, segue abaixo o Quadro 3, contendo o alfabeto latino, o galego e o português, acompanhados de suas transcrições fonéticas com base nas Normas (2012), em Amarante (2015) e em Seara, Nunes e Volcão (2015). Tem-se o objetivo de demonstrar o conservadorismo mantido pelo galego, o que o torna ainda próximo do latim reconstituído, e sua comparação com o português, língua que recentemente sofreu alterações na busca pela unificação de sua ortografia (BRASIL, 2008), já que a mesma está presente em todos os continentes: 
v. 7 (2)

$107-131$ ago/dez 2017

Quadro 3 - Os alfabetos latino, galego e português com suas respectivas realizações fonéticas

\begin{tabular}{|c|c|c|}
\hline Latim reconstituído & Galego & Português \\
\hline $\begin{array}{l}\text { A [a:], [a] } \\
\text { B [b] } \\
\text { C [k] } \\
\text { D [d] } \\
\text { E [e:], [e] } \\
\text { F [f] } \\
\text { G [g] } \\
\text { H[h] } \\
\text { I [i:], [i], [y] } \\
- \\
\text { K [k] } \\
\text { L [l] } \\
\text { M [m] } \\
\text { N [n] } \\
- \\
O \text { [o:], [O] } \\
\text { P [p] } \\
\text { Q [k] } \\
\text { R [r] } \\
\text { S [s] } \\
\text { T [t] } \\
- \\
\text { V [w] } \\
- \\
X[\mathrm{ks}] \\
Y \text { Y }] \\
Z \text { Z [z] }\end{array}$ & $\begin{array}{l}\text { A [a] } \\
\mathrm{B}[\mathrm{b}] \\
\mathrm{C}[\mathrm{s}],[\mathrm{k}] \\
\mathrm{D}[\mathrm{d}] \\
\mathrm{E}[\mathrm{e}],[\mathrm{e}] \\
\mathrm{F}[\mathrm{f}] \\
\mathrm{G}[\mathrm{g}] \text { ou }[\mathrm{h}] \\
\mathrm{H}[-] \\
\mathrm{I}[\mathrm{i}] \\
- \\
- \\
\mathrm{L}[\mathrm{l}] \\
\mathrm{M}[\mathrm{m}] \\
\mathrm{N}[\mathrm{n}] \\
\widetilde{N}[\mathrm{n}] \\
\mathrm{O}[\mathrm{o}],[\mathrm{O}] \\
\mathrm{P}[\mathrm{p}] \\
\mathrm{Q}[\mathrm{k}] \\
\mathrm{R}[\mathrm{r}],[\mathrm{r}] \\
\mathrm{S}[\mathrm{s}] \\
\mathrm{T}[\mathrm{t}] \\
\mathrm{U}[\mathrm{u}] \\
\mathrm{V}[\mathrm{b}] \\
- \\
X[\mathrm{~g}],[\mathrm{ks}] \\
- \\
\mathrm{Z}[\mathrm{s}]\end{array}$ & $\begin{array}{l}\mathrm{A}[\mathrm{a}],[\mathrm{e}] \\
\mathrm{B}[\mathrm{b}] \\
\mathrm{C}[\mathrm{s}],[\mathrm{k}] \\
\mathrm{D}[\mathrm{d}],[\mathrm{d} 3] \\
\mathrm{E}[\mathrm{e}],[\mathrm{e}],[\mathrm{i}] \\
\mathrm{F}[\mathrm{f}] \\
\mathrm{G}[\mathrm{g}],[\mathrm{C}],[\mathrm{gw}] \\
\mathrm{H}[-] \\
\mathrm{I}[\mathrm{i}],[\mathrm{j}] \\
\mathrm{J}[\mathrm{3}] \\
\mathrm{K}[\mathrm{k}] \\
\mathrm{L}[\mathrm{l}],[\mathrm{w}] \\
\mathrm{M}[\mathrm{m}] \\
\mathrm{N}[\mathrm{n}] \\
- \\
\mathrm{O}[\mathrm{o}],[\mathrm{O}],[\mathrm{J}] \\
\mathrm{P}[\mathrm{p}] \\
\mathrm{Q}[\mathrm{k}],[\mathrm{kw}] \\
\mathrm{R}[\mathrm{r}],[\mathrm{r}] \\
\mathrm{S}[\mathrm{s}],[\mathrm{z}] \\
\mathrm{T}[\mathrm{t}],[\mathrm{t}] \\
\mathrm{U}[\mathrm{u}][\mathrm{w}] \\
\mathrm{V}[\mathrm{v}] \\
\mathrm{W}[\mathrm{w}] \\
X[\mathrm{~g}],[\mathrm{s}],[\mathrm{z}],[\mathrm{ks}] \\
\mathrm{Y}[\mathrm{y}] \\
\mathrm{Z}[\mathrm{z}],[\mathrm{s}]\end{array}$ \\
\hline
\end{tabular}

Fonte: Dados da pesquisa

OQuadro 3, como já foi dito, aborda o alfabeto do latim reconstituído, do galego e do português, juntamente com suas realizações fonéticas. O alfabeto latino, que, de acordo com Amarante (2015), era formado por 23 letras em seu período clássico, formou-se a partir do alfabeto dos povos etruscos que, por sua vez, conceberam o seu a partir do alfabeto grego. Naquele tempo, o alfabeto latino possuía apenas 21 letras, visto que os fonemas Y e $\mathrm{Z}$ eram ausentes e, mais tarde, foram trazidos ao latim para a transcrição de palavras gregas (AMARANTE, 2015).

Como se sabe, o galego não foi originado diretamente do latim, mas sim de um romance originado por ele, o galego-português (MONTEAGUDO, 2012). No entanto, não ter se originado diretamente do latim não impediu que o galego mantivesse alguns aspectos do mesmo. Logo, esse conservadorismo se deve, além da filiação, a questões como o período em que o idioma se manteve estático, abordado por Rodríguez (1996), e por se tratar de uma língua muito antiga: 
Conjunto com o português propriamente dito, temos o já referido idioma da Galiza, e, além disso, em relação genética um pouco mais remota, o mirandês, o guadramilês e o riodonorês, falados na raia trasmontana. De todos estes quatro idiomas o mais importante, e o que apresenta literatura mais antiga, pois ascende à idade média, é o galego (BECHARA, 2010, p. 18).

Dessa forma, é possível compreender que, em meio a alguns idiomas, o galego vem a ser o mais importante por sua literatura antiga, o que acaba por revelar mais um dos motivos pelos quais o galego possui uma fonética tão conservadora, semelhante à fonética latina em sua pronúncia reconstituída. Portanto, é compreensível o fato de o alfabeto galego ser tão semelhante ao alfabeto latino na quantidade de letras, sendo o do galego também composto pelas 23, e nas realizações fonéticas, como será abordado mais adiante.

Entretanto, as semelhanças ainda notadas entre o galego e o latim não querem dizer que aquele não evoluiu de alguma forma, mas tal evolução é pequena comparada à de seu vizinho, o português, que se expandiu até países como Brasil, Portugal, Angola, Cabo Verde, GuinéBissau, de Moçambique, São Tomé e Príncipe e Timor Leste graças aos descobrimentos marítimos dos séculos XV e XVI, quando os portugueses conseguiram ampliar seu império linguístico (CUNHA e CINTRA, 2008).

Ainda observando o Quadro 3, é possível notar que os alfabetos apresentados possuem semelhanças e divergências, a começar pela quantidade de letras. Como já mencionado, os alfabetos galego e latino possuem 23 letras, no entanto, não são todas iguais. Isso quer dizer que, em latim, existiam letras como " $k$ " e " $y$ ", que não são encontradas no alfabeto galego, assim como existem no galego as letras "ñ" e "u" que não existiam no latim reconstituído.

A explicação desses fatos se pauta no argumento dado pelas Normas (2012) de que as grafias " $k$ " e " $y$ " existem em galego somente em palavras advindas de outros idiomas e palavras encontradas em textos do latim medieval. No latim, Amarante (2015) explica que a representação minúscula da letra "V" é "u", assim como sua fonética que, quando em posição de semivogal, é representada pelo fonema [w], ou seja, entende-se que, tendo uma letra que representasse tal som, o de "u" não se fazia necessário à grafia em seu alfabeto. Já a letra "ñ", como já explicado, trata-se de uma palatização na passagem do latim para o galego.

Quando o assunto é o português, é possível notar o quanto tal idioma evoluiu. O alfabeto da língua portuguesa tem, após o Acordo 
v. 7 (2)

$107-131$ ago/dez 2017

Ortográfico, 26 letras. Foram acrescentadas, de acordo com o Decreto $\underline{n^{0}} 6.583$, de 29 de setembro de 2008 , as letras " $k$ " " $w$ " e " $y$ " nos casos de nomes próprios e/ou derivados de outras línguas, como "Franklin" e "Kant", em siglas, símbolos e unidades de medidas. Não ocorre, em português, a letra " $\tilde{n}$ " presente no galego, apesar de que, foneticamente, tal letra é equivalente ao dígrafo palatal português "nh".

A letra " $k$ ", presente hoje no alfabeto da língua portuguesa, não existe no idioma galego, visto que ele é munido da letra "q", que possui o mesmo som da letra que lhe falta. Além do "q", a letra " $\mathrm{c}$ " possui som de " $k$ " no três idiomas analisados, porém, no galego e no português, o " $\mathrm{C}$ " também possui som sibilante de [s], diferentemente do latim, língua em que o "c" possuía somente o som de $[\mathrm{k}]$, como no exemplo dado por Amarante (2015) "Cicĕro", que seria pronunciado em latim reconstituído como [kikero:]. A letra "q" em português também tem som de "kW", como em "aquífero" (GEIGER e SILVA, 2009), exemplo que, antes do Acordo, tinha o " $u$ " marcado com o trema indicando que era pronunciado e átono.

As vogais " $\mathrm{e}$ " e " $\mathrm{o}$ " em latim e em galego têm as mesmas pronúncias, um aberto e outro fechado, assim como no português, no qual há o "e" de "cadeia" e o "e" de "teto", o "o" de "orelha" e o "o" de "toca". Entretanto, de acordo com as tabelas de correspondências entre letras e sons de Seara, Nunes e Volcão (2015), em português também há "e" e "o" átonos, ou seja, ao final das palavras são reduzidas a "i" e "u", respectivamente, como em "pele" e "pato".

A letra "g", em latim, possui somente a pronúncia de oclusiva velar como em "gota", nunca como em "página" (AMARANTE, 2015; FARIA, 1970; CART et. al., 1986; JONES e SIDWELL, 2012), como ocorre no português. No galego, isso ocorre semelhantemente ao latim, porém, antes de "e" ou "i" é empregado o " $u$ ", formando o dígrafo "gu", visto que não existe o som palatal de " $g+e$ " ou " $g+i$ " no galego. Em vez disso, emprega-se o "x", como em "xeral" e "xente", exemplos encontrados escritos no corpo do texto das Normas (2012). Há de se pensar que, em vez de se empregar o " $\mathrm{x}$ " em lugar do "g", poderia ser empregado $\mathrm{o}$ "j", cuja fonética é idêntica. No entanto, isso não seria possível no latim nem no galego, uma vez que não existe a letra "j" ${ }_{13} \mathrm{em}$ ambas as línguas. Acredita-se que, devido à ausência do "j" no latim, o galego

13 As letras "j" e " $v$ ", conhecidas como letras ramistas, só foram incorporadas no alfabeto latino no período do Renascimento (séc. XVI) por Pierre de la Ramée (AMARANTE, 2015). 
também não o tem, sendo também empregado o " $\mathrm{x}$ " nas ocorrências em que, em português, seria empregado o "j", como em "jeito", que é escrito "xeito" em galego.

Nitidamente, o " $\mathrm{x}$ " é uma letra muito rica, e é possível observar sua evolução fonética a partir dos três alfabetos apresentados. No latim, Amarante (2015), Faria (1958) e Cart et al. (1986) definem tal letra como "dúplice", pois sempre tem o som difônico de "ks", como em "táxi". o galego, por sua vez, também possui o " $\mathrm{x}$ " dúplice e, ainda, o som chiado como em "queixo". Já o português, traz o " $x$ " com quatro representações fonéticas que podem ser observadas nas palavras "queixo", "próximo", "exagero" e "táxi".

O "h"14, chamado de letra diacrítica por Bechara (2015), não possui som algum no português e no galego, como é possível observar nos exemplos "hoxe" no galego e "hoje" no português. Em ambos os exemplos, o "h" serve somente de letra modificadora de uma consoante para formar um dígrafo, como já explicado. Segundo Faria (1970, p. 87), "o $h$ era considerado pelos gramáticos latinos como simples sinal de aspiração, com o mesmo valor do espírito grego, ou do $h$ aspirado do inglês". Isso demonstra que, no latim, o "h" não era só uma letra auxiliar e sem som, ele era pronunciado levemente aspirado em início de palavras como, como em "hostis" ou "hostel" em inglês, conforme especifica Faria (1958). Já em posição intervocálica, Garcia (2011, p. 20) afirma que o "h é sempre pronunciado com uma leve aspiração".

A pronúncia da letra "l" é semelhante em latim e em galego, visto que é sempre pronunciada vibrante como em "cola" e "pala", mas nunca como a semivogal u [w], como em "quadril" no português. No entanto, para Seara, Nunes e Volcão (2015), dependendo do dialeto brasileiro, o "l" final pode ser pronunciado como em "lata" e "mal", como ocorre na pronúncia galega e latina. De acordo com Faria (1958, p. 21), o "l" pode ter um tríplice som: "tênue quando geminado, como ille, Mettelus; cheio quando em final de palavra ou de sílaba, ou quando na mesma sílaba venha precedido de uma consoante, com em sol, silua, flauus, clarus; médio nas outras posições, como em lectum, lectus".

Tanto no português quanto no galego, Seara, Nunes eVolcão (2015) e as Normas (2012) concordam que o " $r$ " possui duas representações fonéticas, sendo [r] empregada no começo das palavras como em "rato"

${ }_{14}$ Leite (2016, p. 29) acrescenta que "a letra H nos encontros consonantais CH, PH, RH e TH indica uma aspiração. Assim, soam /kh/, /ph/, /rh/ e /th/. O PH não tem som de F, e sim de P seguindo de aspiração". 
v. 7 (2)

$107-131$ ago/dez 2017

e "roda" e o [r] em posição intervocálica como em "aro" ou "prato". No latim, ocorre que o "r" latino só possui a pronúncia vibrada na ponta da língua, semelhante ao rosnar de um cachorro, como apontam Amarante (2015), Faria (1970), Jones e Sidwell (2012).

A letra "s" é admitida no galego e no latim apenas com o som surdo, como em "russo", exemplo dado por Amarante (2015), e nunca com som de [z] como em "rosa" no português, que apresenta as duas pronúncias. Aliás, Cart et al. (1986, p. 8) afirmam que a letras "s" é "sempre linguodental sibilante surda", ou seja, pronunciada com som de "ss". Já a letra " $z$ "15, letra grega introduzida no latim junto com o "y", possui som de [z] no latim, como em "zebra", conforme asseveram Jones e Sidwell (2012), diferente do galego que só admite " $z$ " com som de [s]. Em contrapartida, o português abarca tanto o " $z$ " de zebra, quanto o "z" de "veloz".

A letra "v" possui um som diferente em cada uma das línguas abordadas. No latim, como já mencionado, é representado como "u" em edições modernas de textos latinos, o que reflete em sua pronúncia. Amarante (2015) cita o exemplo de "v" latino na palavra "iuuenis". Na verdade, a representação gráfica dessa letras se dava como V (maiúsculo) e u (minúsculo), sempre para representar o fonema /w/. No galego, o "v" possui o som bilabial de "b", como em "vento", que é pronunciado como "bento". Já no português, de acordo com Bechara (2015, p. 71), o "v" é proferido a partir da zona de articulação labiodental, como em "vaso". Assim,

As semivogais são duas /i/ e /u/. Distinguem-se das vogais correspondentes por estarem sempre seguidas de vogal, nelas se apoiando: iuba (juba), uita (vida). Com o passar do tempo as semivogais /i/ e / $/$ / adquiriram valor consonantal, distinguindo-se das vogais e passando a corresponder aos fonemas $/ \mathrm{j} / \mathrm{e} / \mathrm{V} /$. Na transcrição atual de textos latinos usamse indiferentemente as letras $i$ ou $j$ e $u$ ou $v$ para representar as antigas semivogais (CARDOSO, 2003, p. 15).

Dessa forma, observando rapidamente o Quadro 3, é nítida a existência de algumas letras cujas realizações fonéticas são idênticas no latim reconstituído e no galego, enquanto que no português tais realizações são mantidas junto às novas que foram adquiridas no

\footnotetext{
${ }^{15} \mathrm{Na}$ verdade, a questão fonética relacionada à pronúncia de [z] é bastante controversa, conforme vários testemunhos antigos constantes na obra Faria (1970) e apontamentos de Cart et al. (1986). Por se tratar de uma letras grega, sua pronúncia era confusa em latim. Touratier (2008), por exemplo, considera a probabilidade de que o " $\mathrm{z}$ " fosse surdo. Dessa forma, a pronúncia aqui apresentada não é consensual, mas adotada no artigo como uma das possíveis formas de realização de [z].
} 
processo de evolução do idioma. Segue abaixo um quadro comparativo munido de exemplos que demonstram, de forma sucinta, que o galego mais se aproxima do latim que o português brasileiro.

Quadro 4 - Exemplos de semelhanças e diferenças em alguns fonemas do latim reconstituído, galego e português.

\begin{tabular}{|c|c|c|c|}
\hline Letras & Latim & Galego & Português \\
\hline D & Dominus > do:minus & Dialecto $>$ dialekto & Dia > d3ia; Dado > dad $v$ \\
\hline $\mathrm{J}$ & - & - & Janela > Zancle \\
\hline $\mathbf{L}$ & Pala $>$ pala & Lectura > lektura & Cola > kOle; Mal > maw \\
\hline $\mathbf{S}$ & Mensa > me:nsa & Coisa > kousa & Sócio > sOsiひ; Rosa> rOze \\
\hline
\end{tabular}

Fonte: Dados da pesquisa

O Quadro 4 apresenta alguns exemplos em que é possível perceber as semelhanças e diferenças nas realizações dos fonemas. Em dominus e "dialecto", por exemplo, a consoante "d" é pronunciada em latim e galego de forma idêntica, podendo ser exemplifica pela palavra portuguesa "dado", já que essa letra, "de um modo geral, [tem] a mesma pronúncia do $d$ português, sendo uma oclusiva linguodental sonora" (FARIA, 1970, p. 84). No entanto, há o "d" de "dia" cuja realização fonética é composta por um chiado em vários lugares do Brasil.

Quanto ao "j", não há realização fonética no latim"16 e no galego. Entretanto, tal consoante, identificada por Battisti (2014) como fricativa palatal, é encontrada no português brasileiro em palavras como "janela". A consoante alveolar "l" é, em latim e galego, sempre pronunciada como em "cola" no português, como é possível observar nos exemplos pala e "lectura".

Não há, em latim ou galego a consoante fricativa retroflexa "s" realizada foneticamente com som de " $\mathrm{z}$ ", outra consoante cujo modo e ponto de articulação são iguais ao da consoante "s". No português, além do "s" de "sócio", pronunciado como no latim e no galego, temse o "s" com som de "z", como ocorre na palavra "rosa".

Diante de toda essa análise, é possível compreender que o galego ainda conserva muitos traços do latim reconstituído, diferentemente do português que muito se distanciou no decorrer do tempo. Também é notável uma escala evolutiva entre os três idiomas, sendo a origem no latim, passando pelo galego, estático por certo tempo, e o português, que seguiu em evolução retendo inúmeras influências das línguas e dialetos com os quais entrou em contato.

\footnotetext{
${ }^{16}$ Segundo Cardoso (2003), quando a letra $i$ passou a ter valor consonantal, passou a corresponder ao fonema $/ \mathrm{j} /$, mas, em latim, $i$ e $j$ são utilizadas indistintamente para representar a antiga semivogal.
} 
v. 7 (2) $107-131$ ago/dez 2017

\section{Considerações finais}

A partir do resgate da origem do galego-português, romance medieval considerado arcaico devido a questões histórico-evolutivas, percebeu-se que, apesar da origem comum, as línguas galega e portuguesa seguiram caminhos evolutivos distintos, inclusive no que diz respeito ao cultivo literário. Isso, no entanto, não impediu que houvesse semelhanças fonéticas capazes de tornar tais idiomas mutuamente inteligíveis.

A hipótese levantada para a questão-problema deste trabalho foi confirmada, uma vez que, de fato, a comparação entre os alfabetos latino, galego e português demonstrou uma forte aproximação entre a realização fonética da língua latina e da galega. Acredita-se que, por hoje ser a língua latina pouco dinâmica e mutável, típico de uma língua não viva, de acordo com os pressupostos aventados por Almeida (2005), sua fonética seria pouco aproximada daquela praticada no galego, língua que, mesmo territorialmente limitada, mantém-se oralizada e viva na região da Galiza, sendo alvo de várias tentativas de normatização da escrita, o que daria força e credibilidade ao idioma diante do castelhano, primeiro idioma oficial de Espanha, também manejado na Galiza. Todavia, ocorreu o contrário: a interrupção do cultivo literário e manutenção verbalizada do galego acabou por torná-lo estático, mais aproximado de sua origem, o latim.

Com base em pressupostos da fonética histórica e da história da língua portuguesa, procedeu-se a um estudo comparativo, que foi didatizado por meio de três quadros, entre os três idiomas selecionados em virtude da inter-relação história e evolutiva. Com tal estudo, baseado documentalmente nas Normas ortográficas e morfolóxicas do idioma galego, construídas conjuntamente entre a Real Academia Galega e o Instituto de Língua Galega, foi possível depreender que o galego é idioma de grande importância histórica graças à sua antiga literatura, ponto que revela um dos motivos pelos quais o galego possui uma fonética tão conservadora e bastante aproximada da fonética latina reconstituída. Além do mais, o português, embora com vários pontos fonéticos comuns ao galego, foi tomando realizações fonéticas distintas e múltiplas por força do contato linguístico com diversos povos nos países colonizados durantes a expansão marítima. Isso fez com que a língua portuguesa adquirisse inúmeras realizações fonéticas afastadas das ocorridas na pronúncia reconstituída da língua latina. 
Assim sendo, sem a pretensão de esgotar o assunto, este trabalho traz contribuições que permeiam a história e o estudo de línguas românicas, constituindo uma fonte comparativa entre três idiomas foneticamente assemelhados, mas com várias nuances a serem destacadas, como de fato o foram. Fica claro, pois, que a área da fonética histórica e a da histórica da língua portuguesa são nichos férteis para o desenvolvimento de pesquisas comparativas, de caráter histórico e documental, permitindo a construção de saberes múltiplos a respeito do português de suas línguas irmãs.

\section{Referências}

ALMEIDA, Napoleão Mendes de. Gramática Metódica da Língua Portuguesa. 45. ed. São Paulo: Saraiva, 2005.

AMARANTE, José. Latinitas - leitura de textos em Língua Latina. Fábulas mitológicas esópicas, epigrama, epístolas. Salvador: EDUFBA, 2015.

AREÁN-GARCIA, Nilsa. A História e a Evolução das Línguas na Galiza, em Portugal e no Brasil. Revista Philologus, ano 17, n. 50. Rio de Janeiro: CiFEFiL, maio/ago. 2011. Disponível em: http://www.filologia.org.br/revista/50/01.pdf. Acesso em: 16 de abr. de 17.

AREÁN-GARCIA, Nilsa, Breve Histórico da Península Ibérica. Revista Philologus, ano 15, n. 45. Rio de Janeiro: CiFEFiL, set./dez.2009. Disponível em: http:// www.filologia.org.br/revista/45/02.pdf. Acesso em: 16 de abr. de 2017.

BANHOS, Alexandre. A Galiza, fronteira de Portugal com Espanha. Portal Galego da Língua, 2006. Disponível em: http://agal-gz.org/faq/lib/exe/fetch. php?media=agalia:n39_a_galiza_fronteira_de_portugal_com_espanha. pdf. Acesso em: 16 de abr. $\overline{d e} 2017$.

BASES PRA UNIFICACION DAS NORMAS LINGÜÍSTICAS DO GALEGO. Madrid: Ediciones Anaya S. A., 1977. Disponível em: http://agal-gz.org/mais/ decretofilgueira/wp-content/uploads/sites/9/2015/05/Bases-pr\%C3\%A1Unificaci\%C3\%B3n-das-Normas-Ling\%C3\%BC\%C3\%ADsticas-doGalego-1977.pdf. Acesso em: 18 de abr. de 2017.

BECHARA, Evanildo. Estudo da língua portuguesa: textos de apoio. Brasília: FUNAG, 2010.. Disponível em: http://funag.gov.br/loja/download/696Estudos_da_lingua_portuguesa.pdf. Acesso em: 20 de abr. de 2017.

BECHARA, Evanildo. Moderna Gramática da Língua Portuguesa. 38. ed. rev. ampl. Rio de Janeiro: Nova Fronteira, 2015.

BRASIL. Acordo Ortográfico da Língua Portuguesa. Decreto no 6.583 de 29 de setembro de 2008. Disponível em: http://www.planalto.gov.br/ccivil_03/_ ato2007-2010/2008/decreto/d6583.htm. Acesso em: 19 de abr. de 2017.

CART, A. et al. Gramática Latina. Tradução e adaptação de Maria Evangelina Villa Nova Soeiro. São Paulo: Editora da Universidade de São Paulo, 1986. 
v. 7 (2) $107-131$ ago/dez 2017

130

CINTRA, Luís Felipe Lindley. Nova proposta de classificação dos dialectos galego-portugueses. Boletim de Filologia, Lisboa, Centro de Estudos Filológicos, v. 22, p. 81-116, 1971.

CASTILHO, Ataliba. Como, onde e quando nasceu a Língua Portuguesa?. In: Museu da Língua Portuguesa, 2009, p. 06, 19, 22, 34. Disponível em: https:// pt.scribd.com/document/71074178/Como-e-Quando-Nasceu-a-LinguaPortuguesa. Acesso em: 14 de abr. de 2017

COUTINHO, Ismael de Lima. Pontos de Gramática Histórica. 6. ed. Rio de Janeiro: Livraria Acadêmica, 1974.

CUNHA, Celso; CINTRA, Luis Felipe Lindley. Nova Gramática do Português Contemporâneo. 5. ed. Rio de Janeiro: Lexicon, 2008.

DEBOWIAK, Przemyslaw. Nota sobre os dialectos de Portugal. Romanica Cracoviensia Jagiellonian University Press, Universidade Jagellónica de Cracóvia, 08/2008, p. 21-28, 2008. Disponível em: http://www.wuj.pl/ UserFiles/File/Romanica\%20Cracoviensia\%202008/3-RC-8-Debowiak.pdf. Acesso em: 14 de abr. de 2017.

FARIA, Ernesto. Fonética histórica do latim. 2. ed. Rio de Janeiro: Livraria Acadêmica, 1970.

FARIA, Ernesto. Gramática Superior da Língua Latina. Rio de Janeiro: Livraria Acadêmica, 1958.

GARCIA, Janete Melasso. Introdução à teoria e prática do latim. 3. ed. Brasília: Editora da Universidade Brasília, 2011.

GEIGER, Paulo; SILVA, Renata de Cássia Meneses da. A nova Ortografia sem mistérios: do ensino fundamental ao uso profissional. Rio de Janeiro: Lexicon, 2009.

JONES, Peter; SIDWELL, Keith. Aprendendo latim: textos, gramática, vocabulário, exercícios. Tradução de Isabella Tardin Cardoso e Paulo Sérgio de Vasconcelos. São Paulo: Odysseus Editora, 2012.

LEITE, Leni Ribeiro. Latine loqui - curso básico de latim - volume I. Vitória: EDUFES, 2016.

MONTEAGUDO, Henrique. A Galiza e o espaço linguístico-cultural de expressão portuguesa. In: LOBO, Tânia; CARNEIRO, Zenaide; SOLEDADE, Juliana; ALMEIDA, Ariadne; RIBEIRO, Silvana (orgs.). Rosae: linguística histórica, história das línguas e outras histórias. Salvador: EDUFBA, 2012, pp. 51-64. Disponível em: http://books.scielo.org/id/67y3k/pdf/lobo-978852321230806.pdf. Acesso em: 14 de abr. de 2017.

NUNES, Joaquim José. Compêndio de Gramática Histórica. 7. ed. Lisboa: Livraria Clássica Editora, 1969.

OTHERO, Gabriel de Ávila. Introdução à História da Língua Portuguesa. Pará de Minas (MG): Virtual Books Online, 2003. Disponível em: https://www.google.com.br/url? sa =t\&rct $=j \& q=\&$ esrc $=$ s\&source $=$ web $\& c d=2 \&$ ved $=0$ ahUKEwidjd - CupfOAhVDD5AKHb2EBzAQFgglMAE\&ur $\mathrm{l}=\mathrm{http} \% 3 \mathrm{~A} \% 2 \mathrm{~F} \% 2 \mathrm{FwWw}$.uern.br\%2Fprofessor\%2Farquivo_baixar. 
sg=AFQjCNERRdc51B1LHtOo6ZMZeSRyJqt7pw\&bvm=bv.128617741, d. Y2I\&cad=rja. Acesso em: 15 de abr. de 2017

REAL ACADEMIA GALEGA. Normas ortográficas e morfolóxicas do idioma galego. Instituto da Língua Galega, 23. ed., 2012. Disponível em: http://academia.gal/documents/10157/704901/ Normas + ortogr\%C3\%A1ficas +e+morfol\%C3\%B3xicas+do+idioma+galego . pdf. Acesso em: 14 de abr. de 2017.

RODRÍGUEZ, Alfredo Maceira. Galego e português modernos: um estudo comparativo. Revista Philologus, Rio de Janeiro, v. 6, p. 30-37, 1996. Disponível em: http://www.filologia.org.br/revista/artigo/2(6)30-37.html. Acesso em: 15 de abr. de 2017.

SEARA, Izabel Christiane; NUNES, Vanessa Gonzaga; VOLCÃO, Cristiane Lazarotto. Para conhecer fonética e fonologia do português brasileiro. São Paulo: Contexto, 2015.

SILVA, José Pereira da. Gramática Histórica da Língua Portuguesa. 1. ed. Rio de Janeiro: Intragráfica, 2010.

TEYSSIER, Paul. História da Língua Portuguesa. Tradução de Celso Cunha. Paris: Martins Fontes, 1982. Disponível em: https://disciplinas.stoa. usp.br/pluginfile.php/158086/mod_resource/content/1/TEYSSIER_\%20 HistoriaDaLinguaPortuguesa.pdf. Acesso em: 15 de abr. de 2017.

TOURATIER, Christian. Grammaire Latine. Paris: Armand Colin, 2008.

XIMENES, Expedito Eloísio. Alguns termos da linguística histórica. Revista Philologus, ano 9, n. 25, Rio de Janeiro CIFEFIL, jan./abr. 2003, p. 45-61. Disponivel em: http://www.filologia.org.br/rph/ANO09/25/RPh25.pdf. Acesso em: 14 de abr. de 2017.

WILLIAMS, Edwin. Do Latim ao Português. 4. ed. Tradução de Antônio Houaiss. Rio de Janeiro: Tempo Brasileiro, 1986.

Recebido em: 06 de jul. de 2017.

Aceito em: 2 de ago. de 2017. 